\title{
Aclimatização de mudas micropropagadas de bananeira 'Grand Naine' com aplicação de biofertilizantes em duas estações do ano
}

\author{
Edson Shigueaki Nomural, Erval Rafael Damatto Junior², Eduardo Jun Fuzitani', \\ Luis Alberto Saes ${ }^{1}$, Evelyn Jensen ${ }^{3}$
}

\begin{abstract}
RESUMO
A utilização de mudas de bananeira micropropagadas de qualidade é o primeiro passo na implantação de um bom pomar e, para isso, sua aclimatização deve ser realizada de forma adequada. Em vista disso, objetivou-se, neste trabalho, avaliar o desempenho dos biofertilizantes HUMITEC ${ }^{\circledR}$ e RUTER AA ${ }^{\circledR}$ no desenvolvimento de mudas de bananeira micropropagadas, sendo instalado um experimento em viveiro comercial de produção de mudas. Foram utilizadas mudas de bananeira cv. Grand Naine, obtidas por micropropagação, sendo, posteriormente, transplantadas em sacos de polietileno preto (1,5 L), contendo, como substrato, terra de subsolo (Latossolo Amarelo), casca de arroz carbonizada e composto orgânico Organifol ${ }^{\oplus}$ (1:1:1). O delineamento experimental foi em blocos ao acaso, fatorial 2 x 4 (produtos e doses), com quatro repetições e quatro plantas úteis por parcela. Os tratamentos foram compostos pelos

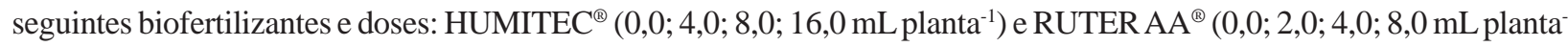
${ }^{1}$ ). As doses dos produtos foram divididas em duas aplicações ( 28 e 56 dias após o transplantio das mudas), aplicadas via fertirrigação. Noventa e oito dias após o transplantio avaliaram-se as seguintes variáveis: altura das plantas $(\mathrm{cm})$, diâmetro do colo rente à superfície do solo (mm), área foliar total e por folha, biomassas fresca e seca da parte aérea e das raízes ( $\mathrm{g}$ ). Os dados foram submetidos à análise da variância e quando o teste $\mathrm{F}$ foi significativo, realizou-se análise de regressão. Pode-se concluir que aplicações de HUMITEC ${ }^{\circledR}$ e RUTER AA ${ }^{\circledR}$ favoreceram o desenvolvimento das mudas e que, no verão, as plantas apresentaram maior desenvolvimento durante a aclimatização.
\end{abstract}

Palavras-chave: desenvolvimento, micropropagação, Musa spp., Humitec ${ }^{\circledR}$, Ruter AA ${ }^{\circledR}$.

\section{ABSTRACT}

\section{Acclimatization of micropropagated 'Grand Naine' banana seedling with application of biofertilizers in two seasons}

The use of quality micropropagated banana seedlings is the first step for a successful orchard establishment and the acclimatization of seedlings must be done properly. This study aimed to evaluate the performance of the biofertilizers HUMITEC $^{\circledast}$ and RUTER AA ${ }^{\circledR}$ on the development of micropropagated banana seedlings produced in commercial seedling nurseries. Seedlings of cv. Grand Naine were obtained via micropropagation and subsequently transplanted into black polyethylene bags $\left(1.5 \mathrm{~L}\right.$ ) containing subsurface soil (oxisol), rice hulls and the organic compost Organifol ${ }^{\circledR}$ (1:1:1). The experiment was arranged in a 2 x 4 factorial randomized blocks design (products and rates) with four replications and four plants per plot. The treatments were consisted of the following rates of biofertilizers: HUMITEC ${ }^{\circledR}$ $\left(0.0,4.0,8.0,16.0 \mathrm{~mL} \mathrm{plant}^{-1}\right)$ and AA RUTER ${ }^{\circledast}\left(0.0,2.0,4.0 ; 8.0 \mathrm{~mL}^{-1 a n t^{-1}}\right)$. Product rates were divided in two applications

Recebido para publicação em 24/01/2012 e aprovado em 07/08/2012

${ }^{1}$ Engenheiros-Agrônomos, Mestres. Agência Paulista de Tecnologia dos Agronegócios (APTA), Pólo Regional Vale do Ribeira, Caixa Postal 122, 11900-000, Registro, São Paulo, Brasil. edsonnomura@apta.sp.gov.br (autor correspondente); edufuzitani@apta.sp.gov.br; luisalbertosaes@apta.sp.gov.br

${ }^{2}$ Engenheiro-Agrônomo, Doutor. Agência Paulista de Tecnologia dos Agronegócios (APTA), Pólo Regional Vale do Ribeira, Caixa Postal 122, 11900-000, Registro, São Paulo, Brasil.erval@apta.sp.gov.br

${ }^{3}$ Graduanda em Agronomia. Universidade Estadual Paulista. Campus Experimental de Registro, Rua Nelson Brihi Badur, 430, Vila Tupy, 11900-000, Registro, São Paulo, Brasil. evelynjensen@ registro.unesp.br 
(28 and 56 days after seedling transplanting) applied by fertirrigation. The variables of this experiment were measured after 98 days of transplantation: plant height $(\mathrm{cm})$, stem diameter $(\mathrm{mm})$, total leaf area and individual leaf area, fresh and dry mass of shoots and roots (g). Data were submitted to variance analysis and F test, and when the treatment means were significant, regression equations were adjusted. The results showed that application of HUMITEC ${ }^{\circledR}$ and RUTER $\mathrm{AA}^{\circledR}$ promoted the development of banana seedlings and that the seedlings showed higher development during acclimatization on summer.

Key words: development, micropropagation, Musa spp.; Humitec ${ }^{\oplus}$; Ruter AA ${ }^{\oplus}$.

\section{INTRODUÇÃO}

Atualmente, vem crescendo o uso de mudas de bananeiras micropropagadas in vitro. A micropropagação consiste no cultivo de plântulas sob condições assépticas e controladas em laboratório, obtendo-se grande número de mudas em curto tempo (Arias, 1993). Ao serem transplantadas no campo, essas mudas crescem mais rapidamente nos primeiros estádios de desenvolvimento (Arias, 1993) e apresentam precocidade da produção, antecipando o florescimento em até quatro meses, quando se compara com o das plantas oriundas da propagação vegetativa (Zerda, 1991).

No entanto, as mudas produzidas in vitro necessitam de período de aclimatização ex vitro, em viveiro sombreado, e acondicionamento em recipientes contendo substrato apropriado para que atinjam o tamanho adequado para plantio no campo. O substrato utilizado durante a permanência das mudas no viveiro deve apresentar boas características físicas, químicas e biológicas, possibilitando rápido desenvolvimento da muda, bom teor de matéria seca nas partes aérea e radicular, dentre outras características (Yamanishi et al., 2004). Adicionalmente ao uso do substrato, podem ser feitas adubações que ajudem a garantir adequado desenvolvimento das mudas, além de acelerarem consideravelmente o crescimento, reduzindo os custos de produção pelo menor tempo de permanência no viveiro.

Além da adubação química, tem-se recomendado a aplicação de matéria orgânica, que contribui no crescimento das plantas por meio de seus efeitos nas propriedades físicas, químicas e biológicas do substrato, com aumento nas populações de micro-organismos, o que leva a processos bioquímicos importantes, como a degradação de matéria orgânica ou a mineralização de nutrientes. Além disso, o adubo compostado contém substâncias orgânicas importantes, entre as quais estão substâncias húmicas, aminoácidos e álcoois.

Segundo Spedding (1988), as substâncias húmicas constituem-se de ácido húmico, ácido fúlvico e humina e originam-se da degradação química e biológica de resí- duos de plantas e da atividade metabólica de micro-organismos.

A matéria orgânica influencia na fisiologia da planta, sendo que as frações húmica e fúlvica alteram a permeabilidade das membranas celulares, influenciam o transporte ativo dos íons e a nutrição mineral, bem como a atividade relacionada com a síntese proteica (Benedetti et al., 1996); promovem, ainda, a produção de enzimas pela planta e a regulação da pressão osmótica, aumentando, deste modo, a sua resistência à seca (Kononova, 1966). Em trabalho com bananeiras, Russo et al. (1995) observaram que a aplicação foliar de biofertilizante húmico extraído de composto de engaço, nas diluições de 1 e 5\%, promoveu significativamente expansão da área foliar, maiores diâmetro e altura do pseudocaule e aumento da biomassa (peso de matéria seca) de folhas e pseudocaules de plantas de bananeira 'Grande Naine', sob condições de viveiro, quando se compara com os resultados do tratamento controle.

Existem no mercado diversas fontes orgânicas, isoladas ou associadas a nutrientes, dentre elas o HUMITEC ${ }^{\circledR}$, que é um fertilizante organomineral constituído por nitrogênio, potássio e matéria orgânica (ácidos húmico e fúlvico), indicado para ser aplicado em fertirrigação. Possui boa compatibilidade com a maioria dos produtos fitossanitários e adubos foliares, com exceção de óleo mineral, produtos de $\mathrm{pH}$ baixo (ácido) e nitrato de cálcio. O uso do HUMITEC ${ }^{\circledR}$ em diferentes cultivares de batata (Monalisa, Jaette Bintje e Ágata) tem proporcionado excelentes resultados, apontando acréscimo no rendimento de cerca de $40 \%$, no primeiro cultivar, e de $20 \%$ nos demais (Tradecorp Internacional, 2007). O RUTER AA ${ }^{\circledR}$ é um fertilizante organomineral, composto por nitrogênio, fósforo, potássio e micronutrientes; acelera o desenvolvimento do sistema radicular de plantas herbáceas ou lenhosas, promovendo o crescimento das plantas nos primeiros estádios de desenvolvimento.

Diante do exposto, objetivou-se, neste trabalho, avaliar o desenvolvimento de mudas de bananeira 'Grand Naine', micropropagadas, com a aplicação de diferentes doses dos biofertilizantes HUMITEC ${ }^{\circledast}$ e RUTER $^{\circledast}$. 


\section{MATERIAL E MÉTODOS}

O experimento foi conduzido em telado comercial, localizado às margens da Rodovia Regis Bittencourt, Km 462, município de Pariquera-Açú, SP (24³6’31" Sul; 4753'48" Oeste e 25 m s.n.m). Segundo a classificação de Köppen, o tipo climático predominante na região é mesotérmico, tropical, quente e úmido (Af). Dados de uma série de dez anos (2000/2010), da estação meteorológica da APTA - Pólo Regional Vale do Ribeira, registraram temperatura média anual de $21,9^{\circ} \mathrm{C}$ e pluviosidade média anual de $1.650 \mathrm{~mm}$ (CIIAGRO, 2012).

Utilizaram-se mudas de bananeira, oriundas de micropropagação, do cultivar Grand Naine, oriundas de explantes retirados de meristemas apicais de rebentos de bananeira. Devidamente desinfetados, foram acondicionados para adaptação em meio nutritivo MS (Murashige \& Skoog, 1962), com benzilaminopurina (BAP) e ácido 2,4 diclorofenoxiacético (2,4D), previamente autoclavado. Após 20 dias no escuro e 20 dias sob iluminação artificial e temperatura controlada, os explantes foram transferidos para o meio nutritivo MS com BAP, para a multiplicação das plântulas, nas quais ocorreram brotações laterais (3 a 6). A cada 30 dias, realizou-se repicagem ou individualização dessas plântulas por, no máximo, cinco vezes. Posteriormente, as plântulas foram transferidas para enraizamento em frascos com meio MS. Após o enraizamento, as plântulas foram retiradas dos frascos e suas raízes foram lavadas para a retirada do excesso de meio de cultura aderido. As plântulas foram transplantadas em canaletas de $40 \mathrm{~cm}$ de largura e $20 \mathrm{~cm}$ de profundidade, preenchidas com substrato composto por vermiculita e substrato a base de turfa (Sunshine ${ }^{\circledR}$ ), para aclimatização em ambiente protegido, coberto com filme de polietileno transparente. Sessenta dias após o transplantio, quando as mudas apresentavam cerca de cinco centímetros de altura e quatro a cinco folhas, foram arrancadas e plantadas em sacos de polietileno preto $(15 \times 15 \mathrm{~cm})$, preenchidos com cerca de 1,5 L de substrato composto pela mistura de terra de subsolo (latossolo amarelo), casca de arroz carbonizada e composto orgânico comercial Organifol ${ }^{\circledR}$ (1:1:1) e acondicionadas em telado com $50 \%$ de sombreamento. O solo foi coberto com um filme de polietileno preto $(100 \mu \mathrm{m})$ para evitar que as raízes o atingissem.

O delineamento experimental foi em blocos ao acaso, em esquema fatorial $2 \times 4$ (dois produtos e quatro doses), com quatro repetições e quatro plantas por parcela. Os tratamentos foram compostos pelos seguintes produtos e doses: HUMITEC ${ }^{\circledR}(0,0 ; 4,0 ; 8,0$ e $16,0 \mathrm{~mL} /$ planta $)$ e RUTER AA $^{\circledR}(0,0 ; 2,0 ; 4,0$ e 8,0 mL/planta) e instalados em duas estações do ano: inverno/2010 e verão/2011. O HUMITEC $^{\circledR}$ apresenta a seguinte composição: ácidos húmicos $(12,0 \%)$ e ácidos fúlvicos $(3,0 \%)$, associados a cloreto de potássio (4,0\%) e nitrogênio (18,0\%). E o RUTER $\mathrm{AA}^{\circledR}$ é composto por aminoácidos livres $(7,0 \%)$, nitrogênio $(5,5 \%)$, matéria orgânica $(15,0 \%)$, fósforo $(5,0 \%)$ cloreto de potássio (3,5\%), ferro quelatizado em $\operatorname{EDDHA}(0,03 \%)$, zinco quelatizado em $\operatorname{EDTA}(0,08 \%)$, manganês quelatizado em $\operatorname{EDTA}(0,05 \%)$ e molibdênio $(0,1 \%)$.

Foi aplicado um volume de $50 \mathrm{~mL} /$ planta nos diferentes tratamentos (doses de HUMITEC ${ }^{\circledR}$ e RUTER AA ${ }^{\circledR}$ ), sendo as doses dos produtos divididas em duas aplicações, realizadas aos 28 e 56 dias após o transplantio das mudas. A irrigação e o controle fitossanitário foram realizados conforme as recomendações para a cultura, de maneira uniforme em todas as parcelas.

Os dados referentes à medição das mudas foram registrados aos 98 dias após o transplantio e as variáveis mensuradas foram: altura da planta $(\mathrm{cm})$, diâmetro do colo rente à superfície do solo ( $\mathrm{mm})$, biomassas fresca e seca da parte aérea $(\mathrm{g})$, das raízes ( $\mathrm{g}$ ) e área foliar total e por folha $\left(\mathrm{cm}^{2}\right)$. A área foliar total da planta foi calculada por meio do somatório da área das folhas individuais, estimada pela equação $\mathrm{AF}=23,421 * \mathrm{~L}-71,826$ (Paiva et al., 2010), em que: $\mathrm{AF}=$ área foliar e $\mathrm{L}=$ largura da folha. Aárea foliar por folha foi calculada pela divisão da área foliar total pelo número total de folhas. Os dados foram submetidos à análise da variância e quando o teste $\mathrm{F}$ foi significativo, realizou-se análise de regressão utilizando-se o programa Sisvar (Ferreira, 2011).

\section{RESULTADOS E DISCUSSÃO}

Pela Figura 1 (A e B), observa-se que a altura de plantas de bananeiras 'Grand Naine', submetidas às doses crescentes de HUMITEC ${ }^{\circledR}$ e RUTER AA ${ }^{\circledR}$ apresenta diferenças significativas nas duas estações de crescimento em que foi avaliada, exceto para a maior dose de RUTER $\mathrm{AA}^{\circledR}(8,0 \mathrm{~mL} /$ planta $)$ aplicada no verão/2011.

$\mathrm{Na}$ avaliação do inverno/2010, constatou-se que, com o aumento da dose de RUTER AA ${ }^{\circledR}$, as mudas de bananeira tiveram maior desenvolvimento em altura, porém na interação entre as doses crescentes de HUMITEC ${ }^{\circledR}$, ocorreu supressão do desenvolvimento em altura, ocasionando sintomas visuais de excesso de nutrientes (queima de folhas uma semana após a aplicação), o que prejudicou o desenvolvimento das mudas na avaliação final das plantas. Nesse período, o maior desenvolvimento em altura foi obtido com a aplicação de $8,0 \mathrm{~mL} /$ planta de HUMITEC ${ }^{\circledR}$ e 4,0 mL/planta de RUTER AA ${ }^{\circledR}(18,4 \mathrm{~cm})$.

$\mathrm{Na}$ avaliação do verão/2011, observou-se que o desenvolvimento em altura das plantas foi maior à medida que se aumentaram as doses dos produtos. Também constatou-se decréscimo do desenvolvimento em altura nas doses mais altas de HUMITEC ${ }^{\circledR}$ e RUTER AA ${ }^{\circledR}$, porém menos intenso, quando comparado com o constatado na 
avaliação do inverno/2010. No verão/2011, o maior desenvolvimento em altura foi observado com a aplicação de 8,0 mL/planta de HUMITEC ${ }^{\circledR}$ e de RUTER AA ${ }^{\circledR}(23,6$ $\mathrm{cm})$. Por causa das melhores condições de temperatura para o desenvolvimento das plantas, observou-se melhor desempenho em altura ao final da avaliação nessa estação, do que observado na do inverno/2010. Mudas com maior desenvolvimento em altura propiciam rápido pegamento e estabelecimento no campo, reduzindo custos para o controle de plantas daninhas e antecipação do florescimento e da colheita.

Para a característica diâmetro do colo das plantas (Figura 2: A e B), observou-se que a interação foi significativa em diferentes doses de HUMITEC $^{\circledR}$ e RUTER AA $^{\circledR}$, nas duas estações em que foi avaliado. Como observado para altura das plantas, houve melhor desenvolvimento em di-
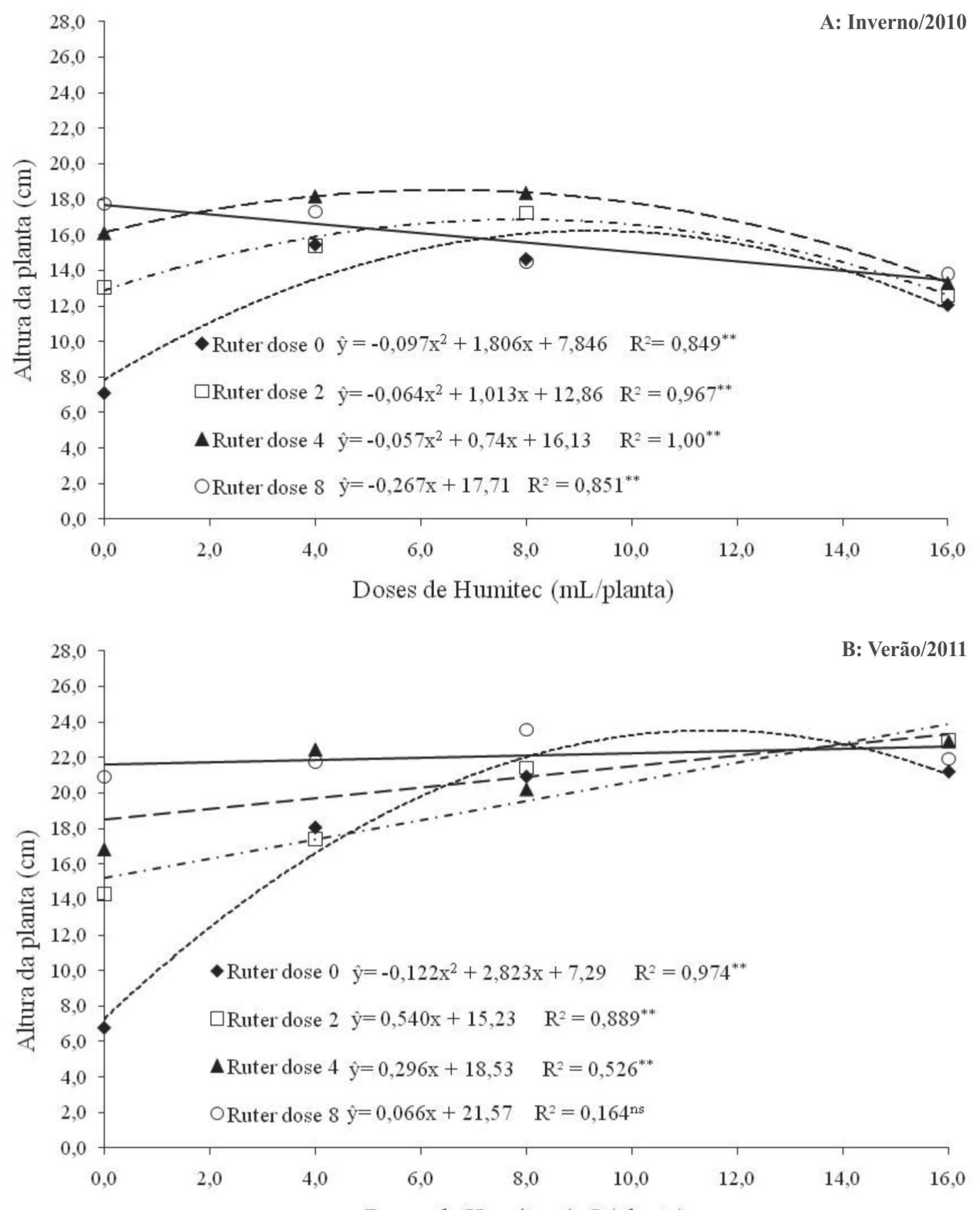

Doses de Humitec ( $\mathrm{mL} /$ planta)

*** significativo $(p>0,01)$; ${ }^{\text {ns }}$ não significativo.

Figura 1. Média de altura (A e B) de mudas de bananeira 'Grand Naine’ tratadas com HUMITEC ${ }^{\circledR}$ e RUTER ${ }^{\circledR}$ e aplicadas em duas estações do ano. 
âmetro no verão/2011, decorrente das melhores condições de temperatura para as plantas. No inverno/2010, com o aumento da dose de HUMITEC ${ }^{\circledR}$ e RUTER AA ${ }^{\circledR}$, observou-se decréscimo no desenvolvimento em diâmetro, comparado com o observado no período de verão/2011, prejudicando a qualidade final das mudas. Os melhores resultados para essa característica foram obtidos nas doses de 4,0 mL/planta de HUMITEC ${ }^{\circledR}$ e de RUTER AA ${ }^{\circledR}$
(22,5 mm), no período de inverno/2010, e nas doses de 8,0 $\mathrm{mL} /$ planta de HUMITEC ${ }^{\circledR}$ e de RUTER AA ${ }^{\circledR}(25,8 \mathrm{~mm})$, no período de verão/2011. Beugnon \& Champion (1966) relatam que existe relação entre o diâmetro do pseudocaule e o número de raízes. Dessa forma, segundo Santos et al. (2004), espera-se que mudas com diâmetros de colo superiores possam originar plantas com sistema radicular mais vigoroso, favorecendo a sobrevivência no campo, o de-

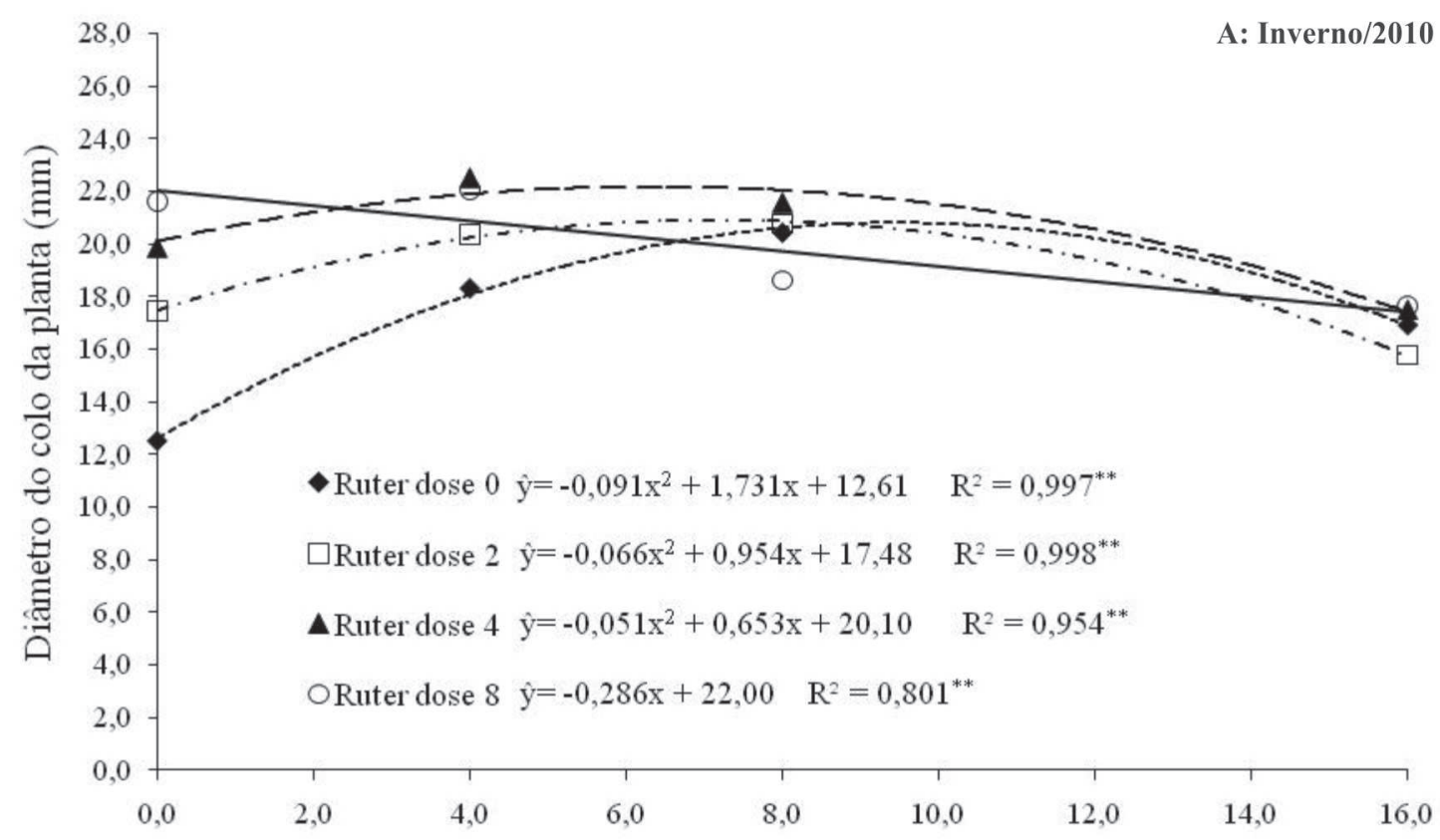

Doses de Humitec (mL/planta)

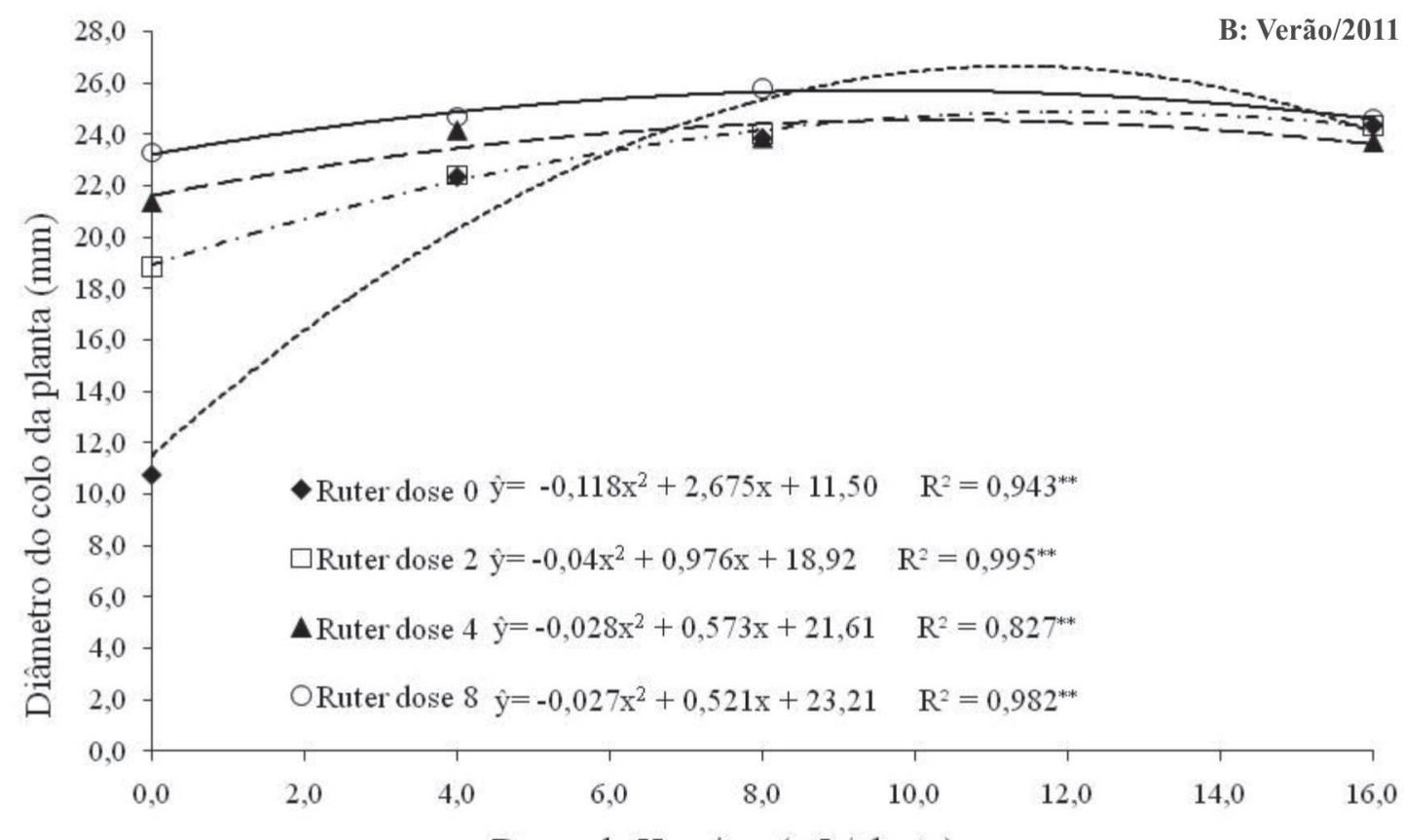

Doses de Humitec (mL/planta)

\footnotetext{
${ }^{* *}$ significativo $(p>0,01)$; ${ }^{\text {ns }}$ não significativo.
}

Figura 2. Média do diâmetro do colo (A e B) de mudas de bananeira 'Grand Naine’ tratadas com HUMITEC ${ }^{\circledR}$ e RUTER ${ }^{\circledR}$ e aplicadas em duas estações do ano.

Rev. Ceres, Viçosa, v. 59, n.4, p. 518-529, jul/ago, 2012 
senvolvimento inicial, a tolerância a veranicos e aos ventos fortes e, consequentente, o aumento da produção.

Na Figura 3 (A e B), observa-se que houve interação significativa das doses de HUMITEC ${ }^{\circledR}{ }^{\circledR}$ e RUTER AA ${ }^{\circledR}$, na produção de biomassa fresca da parte aérea das mudas de bananeiras 'Grand Naine', nas duas estações de avaliação, exceto na maior dose de RUTER AA ${ }^{\circledR}$, no período de verão/2011. As melhores doses dos produtos para a produção de biomassa fresca da parte aérea foram idênticas às obtidas para o diâmetro do colo, nos dois períodos de avaliação (inverno/2010: 128,1 g; verão/2011: $150,9 \mathrm{~g}$ ). Na avaliação do inverno/2010, constatou-se que a aplicação da maior dose de RUTER AA ${ }^{\circledR}$ promoveu decréscimo do acúmulo de matéria fresca da parte aérea de plantas de bananeira, ocasionado pelo excesso de nutrientes e pela falta de condições de temperatura para o seu

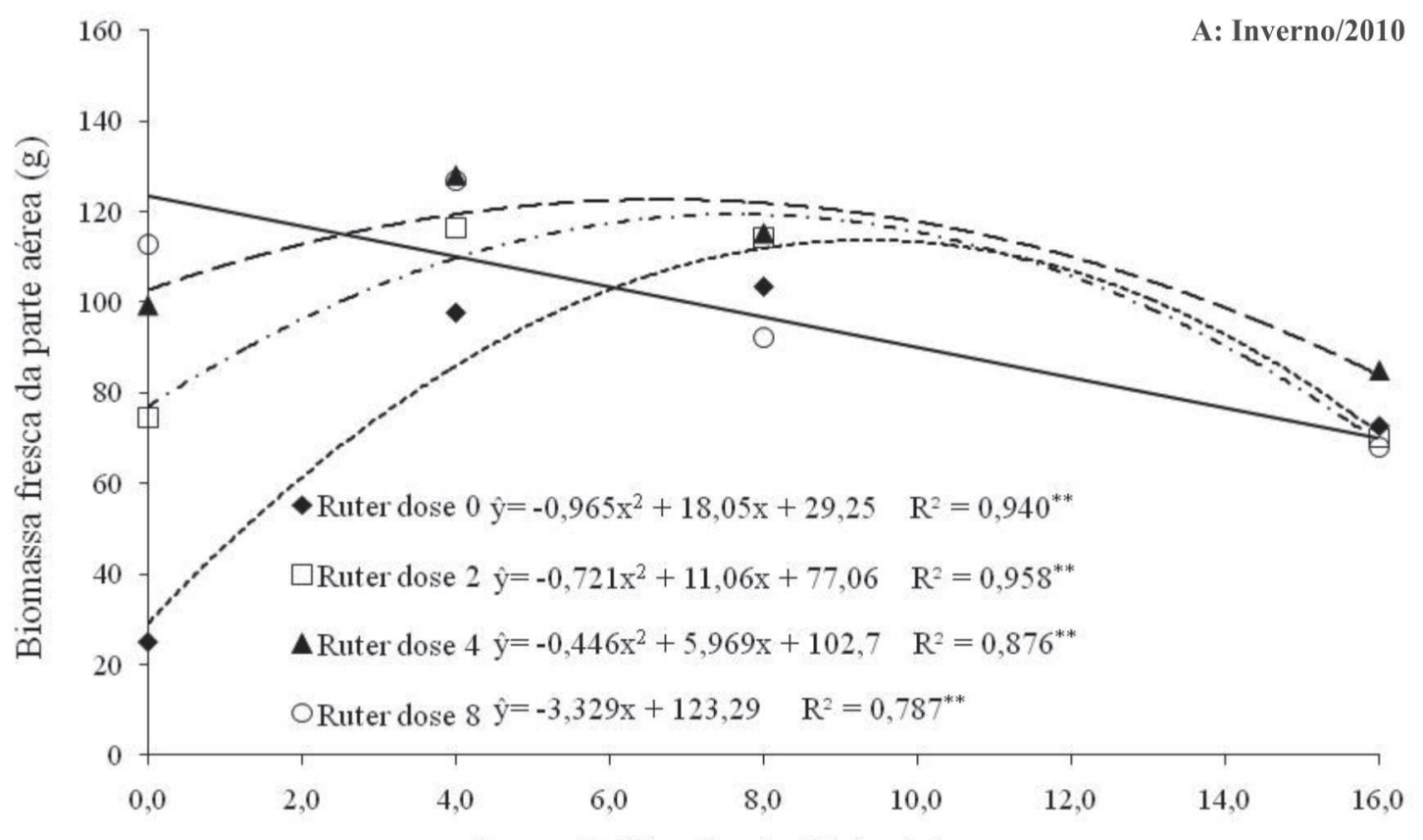

Doses de Humitec ( $\mathrm{mL} /$ planta)

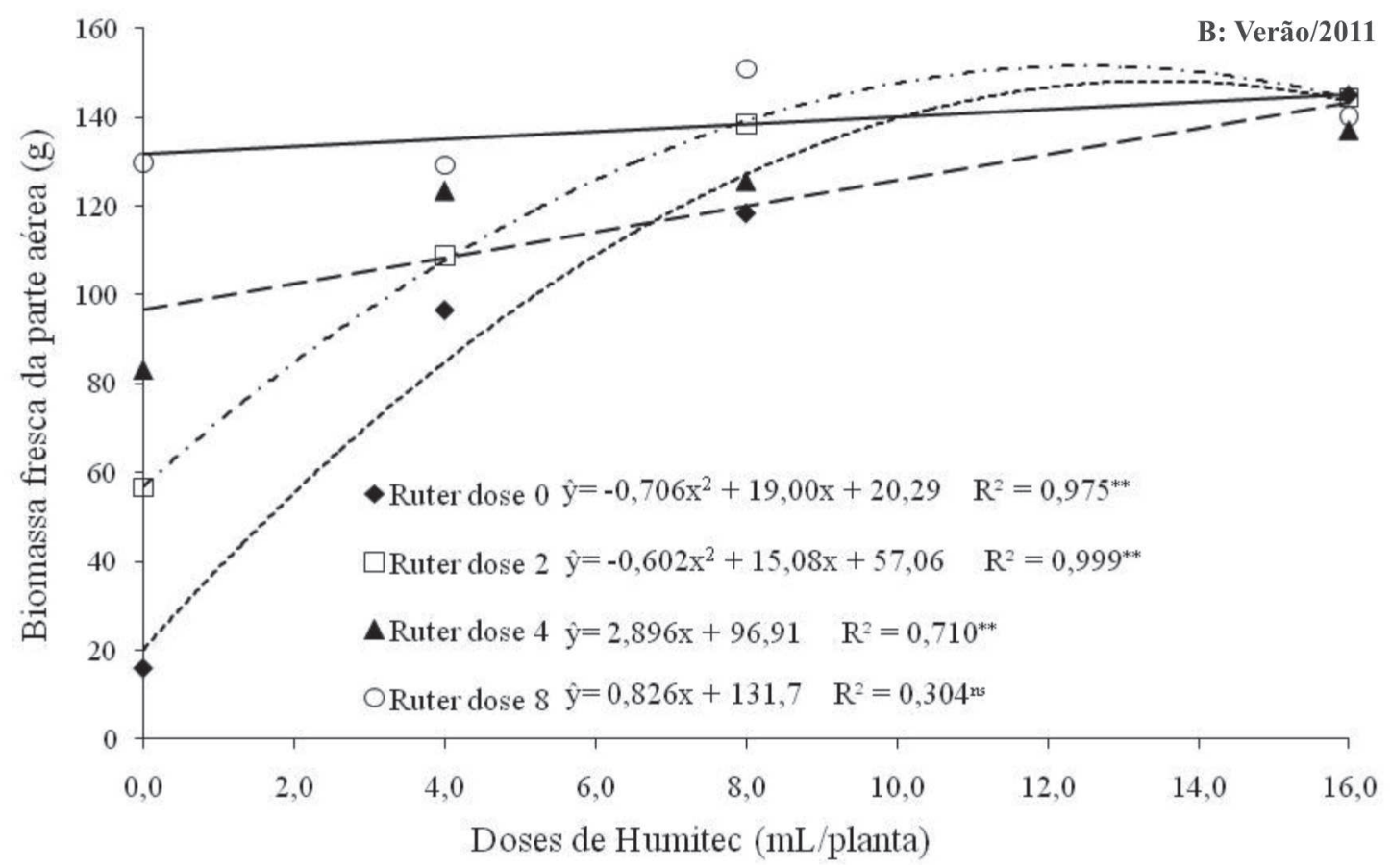

*** significativo $(p>0,01)$; ${ }^{\text {ns }}$ não significativo.

Figura 3. Média da biomassa fresca da parte aérea (A e B) de mudas de bananeira 'Grand Naine' tratadas com HUMITEC ${ }^{\circledR}$ e RUTER $^{\circledR}$ e aplicadas em duas estações do ano. 
desenvolvimento. No entanto, na avaliação do verão/2011 esta tendência foi menor, e ao final do experimento observaram-se mudas de melhor qualidade.

Noventa e oito dias após o transplantio, as mudas de bananeira 'Grand Naine' acumularam maior biomassa seca de parte aérea na dose de 4,0 mL/planta de HUMITEC ${ }^{\circledR}$ e de RUTER AA ${ }^{\circledR}(15,1 \mathrm{~g})$, no período de inverno/2010 (Figura 4; A e B), com redução desse acúmulo com o aumen- to da dose dos dois produtos. No período de verão/2011, também se observou esta tendência, porém, em menor escala.

Na Figura 5 (A e B), observa-se que houve interação significativa entre os produtos para a produção de biomassa fresca das raízes, nas duas estações do ano, exceto na dose de $8,0 \mathrm{~mL} /$ planta de RUTER AA ${ }^{\circledR}$, no verão/2011. Com a aplicação de 8,0 mL/planta de HUMITEC ${ }^{\circledR}$

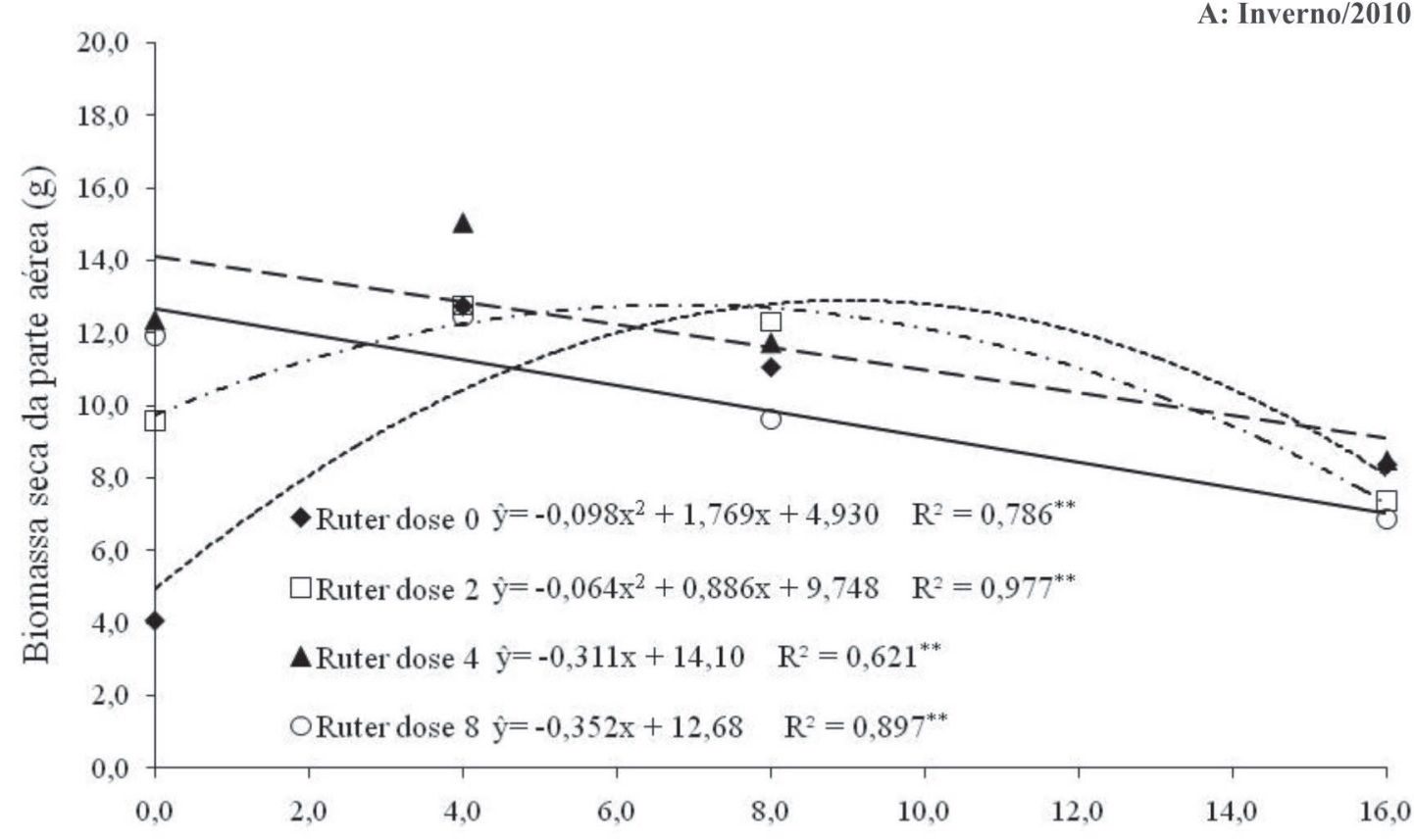

Doses de Humitec $(\mathrm{mL} /$ planta)

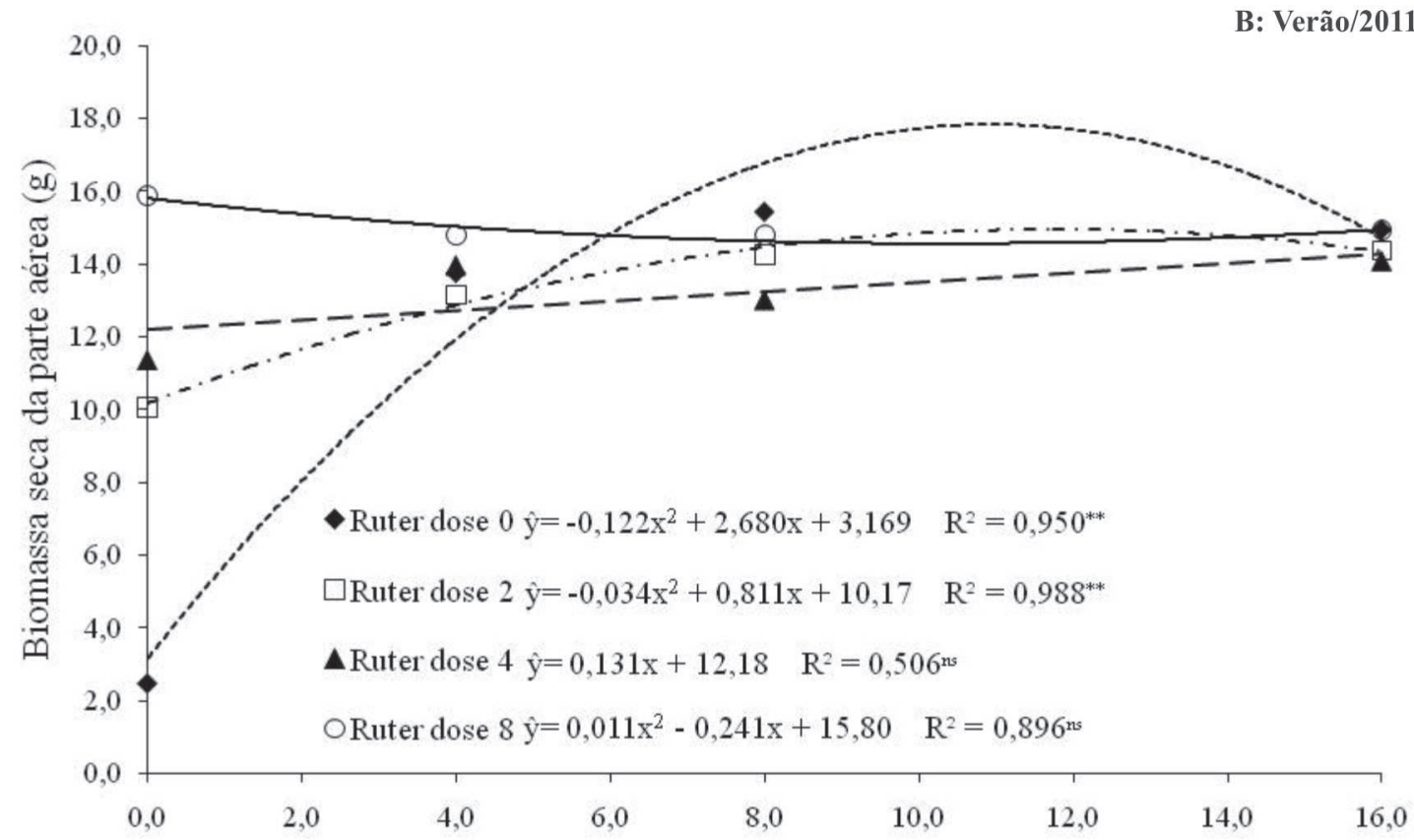

Doses de Humitec $(\mathrm{mL} /$ planta)

** significativo $(p>0,01) ;{ }^{\text {ns }}$ não significativo.

Figura 4. Média da biomassa seca da parte aérea (A e B) de mudas de bananeira 'Grand Naine’ tratadas com HUMITEC ${ }^{\circledR}$ e RUTER ${ }^{\circledR}$ e aplicadas em duas estações do ano.

Rev. Ceres, Viçosa, v. 59, n.4, p. 518-529, jul/ago, 2012 
e RUTER AA ${ }^{\circledR}$, constatou-se que as mudas produzidas no verão/2011 apresentaram maior acúmulo de matéria fresca nas raízes $(59,5 \mathrm{~g})$, quando se compara com o daquelas produzidas no inverno/2010 (41,8 g). Porém, ao avaliar a produção de biomassa seca, a dose de $4,0 \mathrm{~mL} /$ planta de HUMITEC $^{\circledR}$ e de RUTER AA ${ }^{\circledR}$ foi aquela que apresentou maior acúmulo nas duas estações de avaliação (Figura 6: A e B). Ambas as características (biomassas fresca e seca) apresentam tendência de redução de acúmulo com o aumento das doses dos produtos, mais acentuada na avaliação realizada no inverno/2010.

Segundo Stevenson (1994), as substâncias húmicas exercem várias funções nas propriedades químicas, físicas e biológicas do solo; além disso, interferem em processos fisiológicos das plantas, na absorção de nutrientes e no crescimento radicular e da parte aérea de diferentes espé-

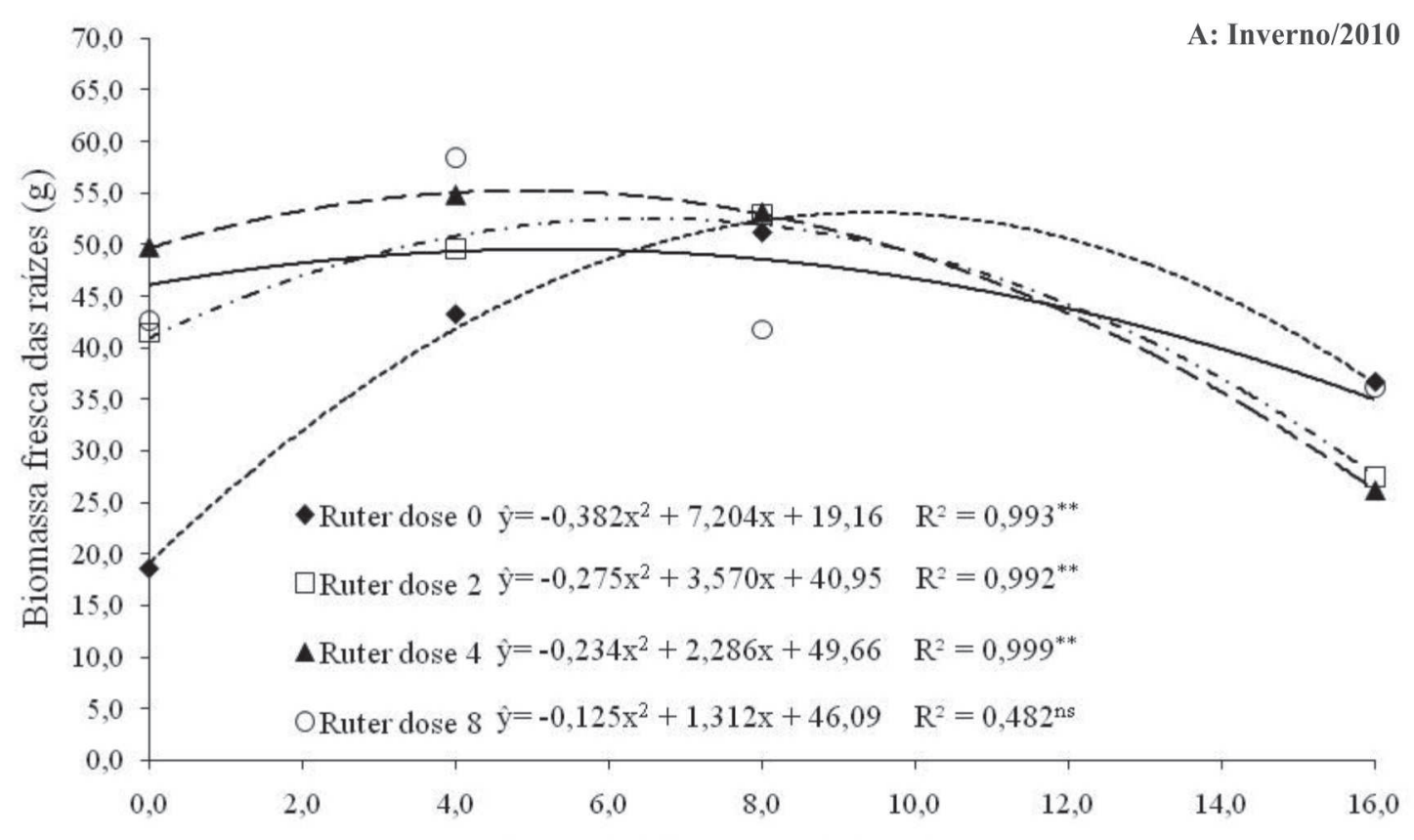

Doses de Humitec (mL/planta)

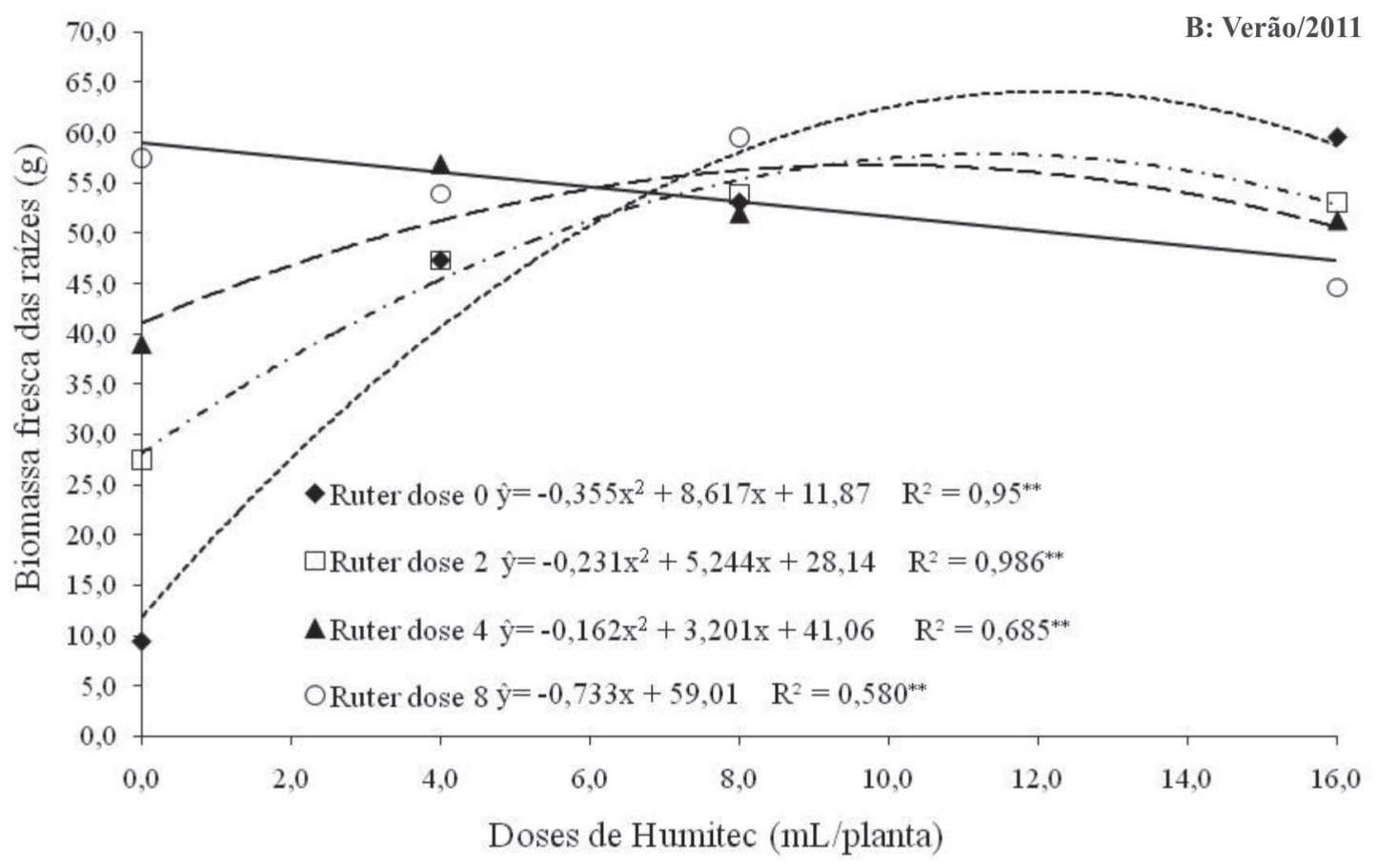

*** significativo $(p>0,01)$; ${ }^{\text {ns }}$ não significativo.

Figura 5. Média da biomassa fresca das raízes (A e B) de mudas de bananeira ‘Grand Naine’ tratadas com HUMITEC ${ }^{\circledR}$ e RUTER ${ }^{\circledR}$ e aplicadas em duas estações do ano. 
cies vegetais (Chen \& Aviad, 1990; Nardi et al., 2002; Rosa et al. 2009). Por outro lado, Figliolia et al. (1994) relataram que em alface (Lactuca sativa L.) e milho (Zea mays L.) a produção foi maior com a aplicação de ácidos húmicos misturados com N-P-K, do que quando se aplicou unicamente N-P-K. A explicação mais provável para este resultado é que a aplicação de ácidos húmicos com N-P-K causou efeito sinérgico na absorção dos nutrientes, no metabolismo microbiano, na bioquímica do solo e com estímulo na fisiologia, principalmente com aumento da atividade enzimática e da fotossíntese das plantas, ocasionando aumento da produção. Segundo Baldotto et al. (2009), a aplicação de ácidos húmicos isolados de vermicomposto e de torta de filtro promoveram o crescimento vegetal de plantas originadas de cultura in vitro de abacaxizeiro 'Vitória', na fase de aclimatação, uma vez que foram observados incremen-
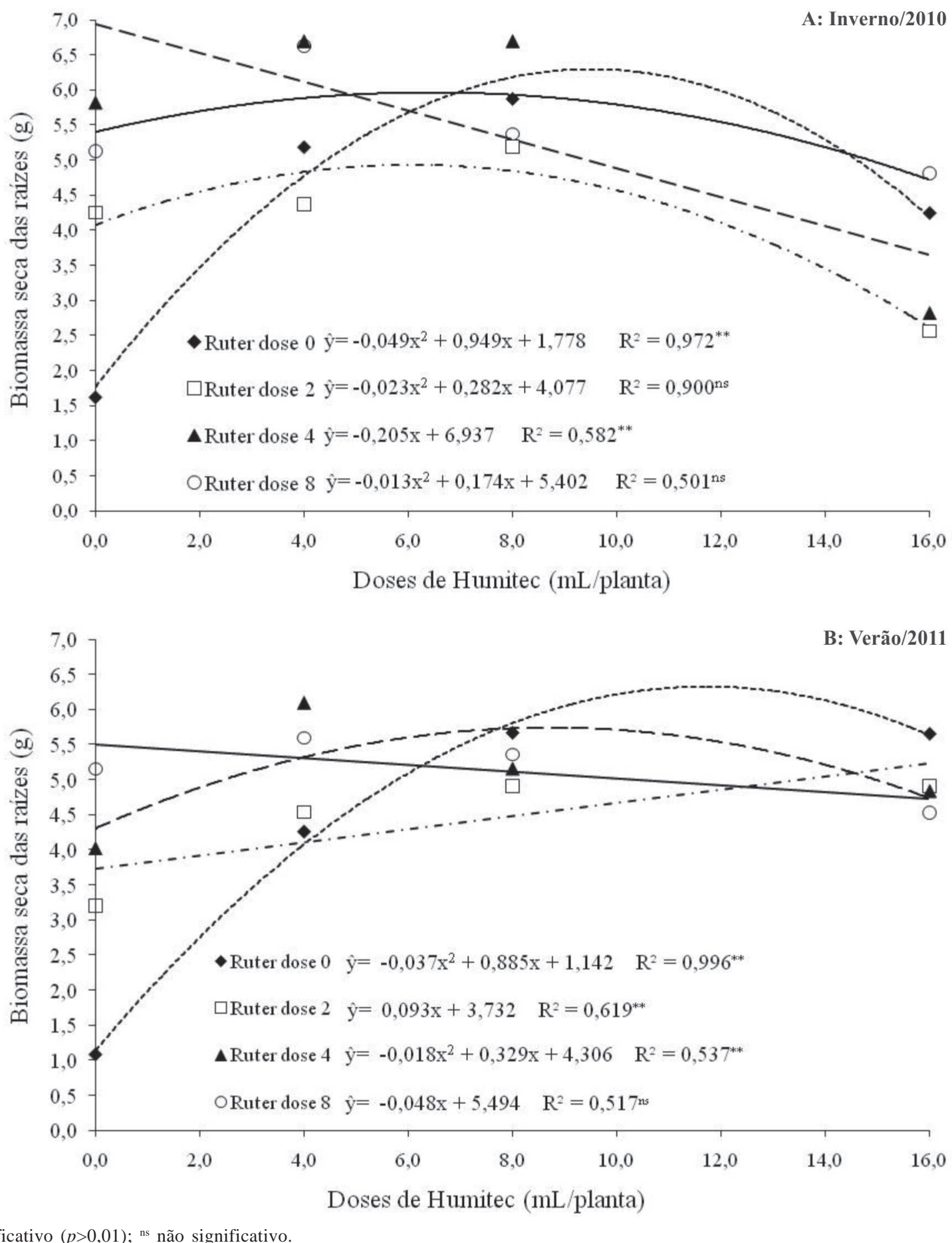

*** significativo $(p>0,01)$; ${ }^{\text {ns }}$ não significativo.

Figura 6. Média da biomassa seca das raízes (A e B) de mudas de bananeira 'Grand Naine' tratadas com HUMITEC ${ }^{\circledR}$ e RUTER ${ }^{\circledR}$ e aplicadas em duas estações do ano.

Rev. Ceres, Viçosa, v. 59, n.4, p. 518-529, jul/ago, 2012 
tos no crescimento da parte aérea, do sistema radicular e nos conteúdos de $\mathrm{N}, \mathrm{P}, \mathrm{K}, \mathrm{Ca}$ e Mg, além de resultar em aumento da relação clorofila $a$ /clorofila $b$.

As características área foliar total (Figura 7) e por folha (Figura 8), no inverno/2010, apresentaram maior desenvolvimento com a dose de 4,0 mL/planta de HUMITEC ${ }^{\circledR}$ e de RUTER AA ${ }^{\circledR}\left(1.309,8\right.$ e $174,9 \mathrm{~cm}^{2}$, respectivamente), decrescendo com o aumento das doses dos dois produ- tos. No entanto, ao se comparar com a avaliação realizada no verão/2011, a melhor dose foi de $8,0 \mathrm{~mL} /$ planta de HUMITEC $^{\circledR}$ e 16,0 mL/planta de RUTER AA ${ }^{\circledR}$, para área foliar total $\left(1.618,9 \mathrm{~cm}^{2}\right)$, e 8,0 mL/planta de HUMITEC ${ }^{\circledR} \mathrm{e}$ de RUTER AA ${ }^{\circledR}$, para área foliar por folha $\left(209,3 \mathrm{~cm}^{2}\right)$, também com tendência de redução de desenvolvimento com o aumento das doses dos produtos, porém com menos intensidade.
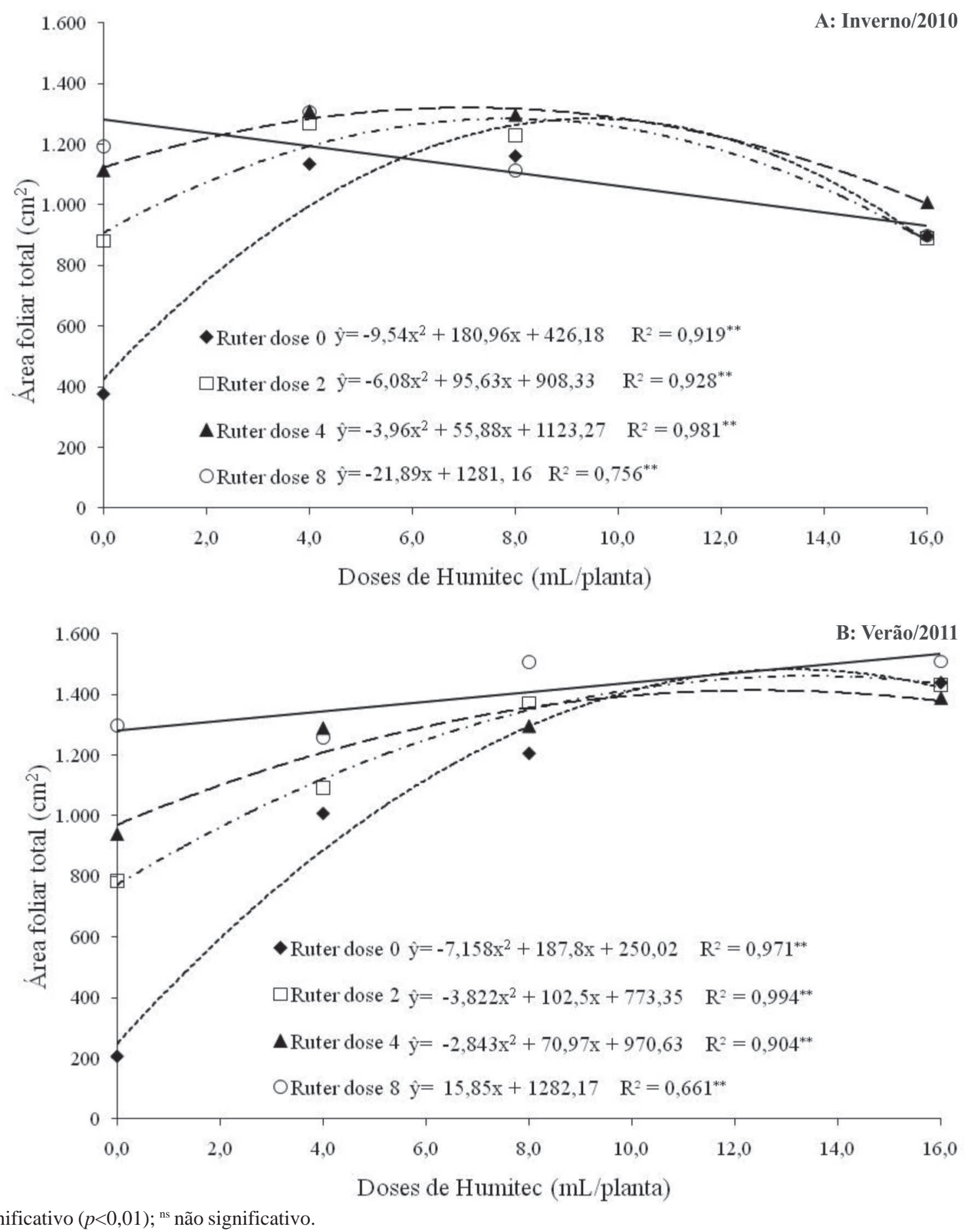

${ }^{* *}$ significativo $(p<0,01) ;{ }^{\text {ns }}$ não significativo.

Figura 7. Média da área folia total (A e B) de mudas de bananeira 'Grand Naine’ tratadas com HUMITEC ${ }^{\circledR}$ e RUTER ${ }^{\circledR}$ e aplicadas em duas estações do ano. 
Mudas com maior área foliar na época de serem transplantadas no campo apresentam rápido crescimento inicial, pela maior produção de fotoassimilados e posterior alocação em outras partes da planta (Kozlowski et al., 1991). Porém, Morgado (1998) considerou a massa da matéria seca da parte aérea como característica que mais contribui para a capacidade de resistência das mudas às condições adversas, após o estabelecimento no campo.
Estudos realizados por Moreira et al. (2006) com a aclimatização de mudas de abacaxizeiro mostraram que o número total de folhas na planta é muito importante, pois quanto maior a área foliar, melhor o índice de sobrevivência no campo, pois são elas as estruturas responsáveis pela captação de energia solar e produção de matéria orgânica por meio da fotossíntese. Mudas de bananeira com maior área foliar total e maior número de folhas, provavel-
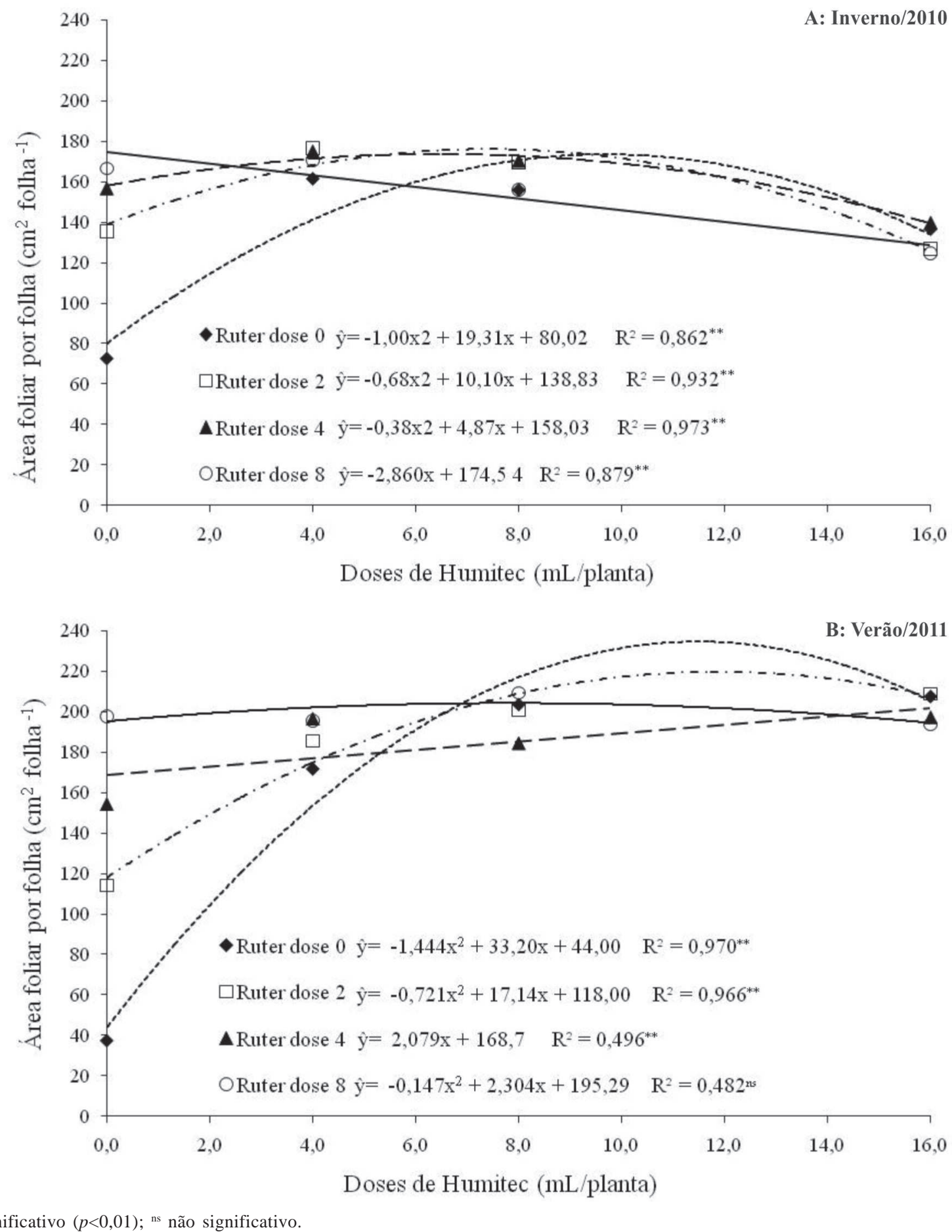

** significativo $(p<0,01)$; ${ }^{\text {ns }}$ não significativo.

Figura 8. Média da área foliar por folha (A e B) de mudas de bananeira 'Grand Naine' tratadas com HUMITEC ${ }^{\circledR}$ e RUTER ${ }^{\circledR}$ e aplicadas em duas estações do ano. 
mente, apresentarão maior índice de pegamento, crescimento inicial e desenvolvimento, por causa da maior produção de fotoassimilados, resultando, possivelmente, em maior produção (Santos et al., 2004).

Diante disso, estes resultados demonstram a importância da utilização de fontes orgânicas para a produção de mudas de bananeiras 'Grand Naine', micropropagadas em laboratório, visto que este estudo indicou que a utilização dos biofertilizantes HUMITEC ${ }^{\circledR}$ e de RUTER AA ${ }^{\circledR}$ apresentou aceleração no desenvolvimento, durante a fase de aclimatização das plantas, e pode representar alternativa para a agricultura orgânica, com a redução de custos de produção, com base no menor uso de mão de obra e na maior eficiência de absorção dos nutrientes.

\section{CONCLUSÕES}

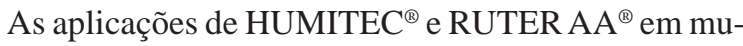
das de bananeira 'Grand Naine' micropropagadas favoreceram todas as características de desenvolvimento avaliadas;

Mudas de bananeiras 'Grand Naine' tratadas com HUMITEC $^{\circledR}$ e RUTER AA ${ }^{\circledR}$ apresentaram maior desenvolvimento no verão.

\section{REFERÊNCIAS}

Arias O (1993) Commercial micropropagation of banana. In: Workshop on Biotechnology Applications for Banana and Plantain Improvement, San José. Proceedings. INIBAP, Montpellier. p.139-142.

Baldotto LEB, Baldotto MA, Giro VB, Canellas LP, Olivares FL \& Bressan-Smith R (2009) Desempenho do abacaxizeiro 'Vitória' em resposta à aplicação de ácidos húmicos durante a aclimatação. Revista Brasileira de Ciência do Solo, 33:979-990.

Benedetti MF, Van Riemsdijk WH, Koopal LK, Kinniburgh DG, Gooddy DC \& Milne CJ (1996) Metal ion binding by natural organic matter: from the model to the field. Geochimica et Cosmochimica Acta, 60:2503-2513.

Beugnon M \& Champion J (1966) Étude sur les racines du bananier. Fruits, 21:309-327.

Chen Y \& Aviad T (1990) Effect of humic substances on plant growth. In: MacCarthy P, Clapp CE, Malcolm RL \& Bloom PR (Eds.) Humic substances in soil and crop sciences: Selected Readings. Madison, ASA and SSSA. p.161-186.

Centro Integrado de Informações Agrometeorológicas (CIIAGRO). Disponível em: <http://www.ciiagro.sp.gov.br/>. Acessado em: 25 de fevereiro de 2012.

Ferreira DF (2011) Sisvar: a computer statistical analysis system. Ciência e Agrotecnologia, 35:1039-1042.

Figliolia A, Benedetti A, Izza C, Indiati R, Rea E, Alianiello F, Canali S, Biondi FA, Pierandrei F \& Moretti R (1994) Effects of fertilization with humic acids on soil and plant metabolism: a multidisciplinary approach. In: Senesi N \& Miano TM (Eds.) Humic Substances in the Global Environment and Implications on Human Health. Bari, Elsevier. p.579-584.

Kononova MM (1966) Soil organic matter. New York, Pergamon Press. 544p.
Kozlowski T, Kramer PJ \& Pallardy SG (1991) The physiological ecology of woody plants. London: Academic. 657p.

Moreira MA, Carvalho JG, Pasqual M, Fráguas C \& Silva AB (2006) Efeito de substratos na aclimatação de mudas micropropagadas de abacaxizeiro cv. Pérola. Ciência e Agrotecnologia, 30:875879 .

Morgado IF (1998) Resíduos agroindustriais prensados como substrato para a produção de mudas de Eucaluptus grandis Hill ex Maiden e Saccharun spp. Tese de doutorado. Universidade Estadual do Norte Fluminense, Campos de Goytacazes. 102p.

Murashige T \& Skoog F (1962) A revised medium for rapid growth and bioassays with tobacco tissue cultures. Physiology Plantarum, 15:473-479.

Nardi S, Pizzeghello D, Muscolo A \& Vianello A (2002) Physiological effects of humic substances on higher plants. Soil Biology and Biochemistry, 34:1527-1536.

Paiva BAR, Malta CG, Costa DP, Naves KC, Teixeira WG, Naves RV \& Seleguini A (2010) Estimativa da área foliar de mudas de quatro variedades de bananeira micropropagadas. In: XXI Congresso Brasileiro de Fruticultura, Natal. Anais, Sociedade Brasileira de Fruticultura. p.1-4

Rosa CM, Castilhos RMV, Vahl LC, Castilhos DD, Pinto LFS, Oliveira ES \& Leal OA (2009) Efeito de substâncias húmicas na cinética de absorção de potássio, crescimento de plantas e concentração de nutrientes em Phaseolus vulgaris L. Revista Brasileira de Ciência do Solo, 33:959-967.

Russo R, Lugo J, Arreola O \& Arango O (1995) Efecto de un bioestimulante húmico extraído del raquis de banano (pinzote) sobre el crecimiento de plántulas de banano (Musa AAA subgrupo "Cavendish" don 'Gran Enano'). Agronomía Mesoamericana, 6:130-133.

Santos JA, Silva CRR, Carvalho JG \& Nascimento TB (2004) Efeito do calcário dolomítico e nitrato de potássio no desenvolvimento inicial de mudas da bananeira 'Prata-Anã' (AAB), provenientes de cultura in vitro. Revista Brasileira de Fruticultura, 26:150-154.

Spedding PJ (1988) Synthèse des travaux sur la caractérisation, la production et l'utilisation de la tourbe, sur les dix dernières années. Fuel, 67:883-900.

Tradecorp Internacional (2007) Humitec $®$ : Mayor rentabilidad en patata - Ensayo comercial, Brasil. Disponível em: <http:// w w w.tradecorp.com.es/_es/internet/webteca/ article.asp?id_Artigo=263>. Acessado em: 15 de janeiro de 2011.

Stevenson FJ (1994) Humus chemistry: Genesis, composition, reactions. New York, John Wiley \& Sons. 496p.

Yamanishi OK, Fagundes GR, Machado Filho JA \& Valone GV (2004) Efeito de diferentes substratos e duas formas de adubação na produção de mudas de mamoeiro. Revista Brasileira de Fruticultura, 26:276-279.

Zerda AA (1991) Successes and prospects in biotechnology in Colômbia: the case of bananas and flowers. Revista Nacional de Agricultura, 897:89-94. 